$4-5-2001$

\title{
Determination of Lysophosphatidic Acids by Capillary Electrophoresis with Indirect Ultraviolet Detection
}

\author{
Yi Lung Chen \\ Cleveland State University \\ Yan Xu \\ Cleveland State University, y.xu@csuohio.edu
}

Follow this and additional works at: https://engagedscholarship.csuohio.edu/scichem_facpub

Part of the Analytical Chemistry Commons

How does access to this work benefit you? Let us know!

\section{Publisher's Statement}

NOTICE: this is the author's version of a work that was accepted for publication in Journal of Chromatography B: Biomedical Sciences and Applications. Changes resulting from the publishing process, such as peer review, editing, corrections, structural formatting, and other quality control mechanisms may not be reflected in this document. Changes may have been made to this work since it was submitted for publication. A definitive version was subsequently published in Journal of Chromatography B: Biomedical Sciences and Applications, 753, 2, April 5, 2001 DOI\#10.1016/S0378-4347(00)00582-X

\section{Recommended Citation}

Chen, Yi Lung and Xu, Yan, "Determination of Lysophosphatidic Acids by Capillary Electrophoresis with Indirect Ultraviolet Detection" (2001). Chemistry Faculty Publications. 178.

https://engagedscholarship.csuohio.edu/scichem_facpub/178

This Article is brought to you for free and open access by the Chemistry Department at EngagedScholarship@CSU. It has been accepted for inclusion in Chemistry Faculty Publications by an authorized administrator of EngagedScholarship@CSU. For more information, please contact library.es@csuohio.edu. 


\title{
Determination of lysophosphatidic acids by capillary electrophoresis with indirect ultraviolet detection
}

\author{
Yi-Lung Chen, Yan Xu
}

\section{Introduction}

Lysophosphatidic acid (LPA) is the simplest form of lysophospholipid (Lyso-PL) (Fig. 1). LPA belongs to the phospholipid (PL) family, and bears only one fatty acyl group. LPA is not only a membrane component and metabolic intermediate but also an intercellular messenger with a role in cell growth and motility [1]. LPAs have also been identified as the potent components in an ovarian cancer activation factor (OCAF) from ascitic fluid of ovarian cancer patients [2]. The OCAF that comprises various molecular species of LPA with different fatty acyl chains (i.e., palmitoyl, stearoyl, oleoyl, linoleoyl, arachidonoyl and docosahexarnoyl) stimulates calcium release, tyrosine phosphorylation and the proliferation of ovarian cancer cells. Recent studies $[3,4]$ show that the elevated plasma LPAs may be used as potential biomarkers for the early detection of ovarian cancer.

Traditionally, gas chromatography (GC) and liquid chromatography (LC) have been used to measure PLs [5,6]. Despite their high analytical sensitivity, these methods often require laborious sample pretreatment, derivatization, or lengthy separation. Therefore, a simple and efficient analytical method is needed for PLs analysis.

Capillary electrophoresis (CE) is well known for its high separation efficiency, application versatility, and instrument simplicity. While the methodologies 


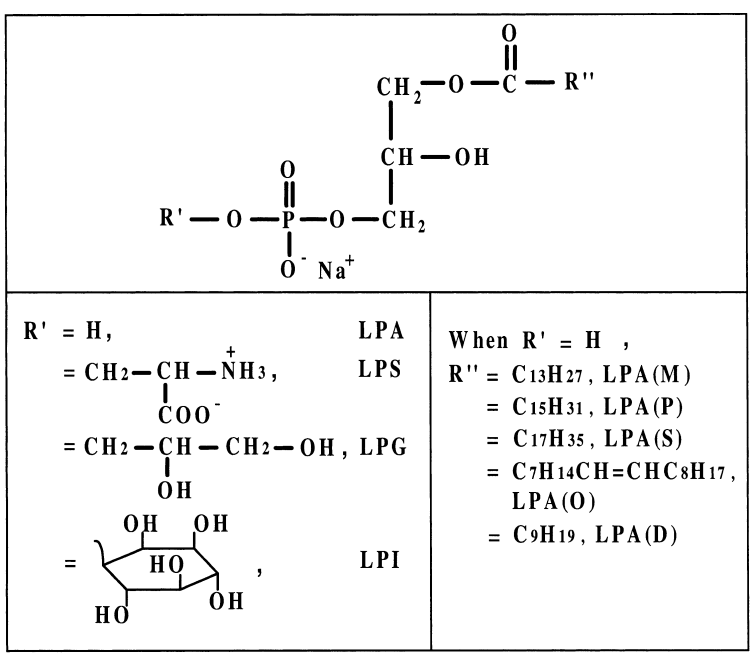

Fig. 1. The molecular structures of lysophospholipids.

of CE are well established for analyzing a variety of substances [7], its application for lipid analysis is limited. Only a few papers on the separation of PLs have been published [8-11], which include two micellar electrokinetic capillary chromatographic methods [8,9], one CE-mass spectrometric method [10], and one CE-indirect ultraviolet (UV) method [11].

In this work, a CE method using indirect UV detection for the determination of molecular species of LPA has been developed. The optimum CE conditions were investigated and the internal calibration plots for LPAs were established. The method has been applied to the analysis of LPAs in serum. This paper is the first report on the quantitative analysis of LPAs by CE.

\section{Experiment}

\section{Chemicals and solutions}

Lysophosphatidic acids (synthetic, purity $>99 \%$ ) [1-myristoyl-2-hydroxy-sn-glycero-3-phosphate monosodium salt, LPA (M); 1-palmitoyl-2-hydroxy-snglycero-3-phosphate monosodium salt, LPA (P); 1-stearoyl-2-hydroxy-sn-glycero-3-phosphate mono- sodium salt, LPA (S); 1-oleoyl-2-hydroxy-snglycero-3-phosphate monosodium salt, LPA (O); and 1-decanoyl-2-hydroxy-sn-glycero-3-phosphate monosodium salt, LPA (D)]; 1-palmitoyl-2-hydroxy-snglycero-3-phosphocholine (synthetic, purity $>99 \%$ ), LPC (P); 1-palmitoyl-2-hydroxy-sn-glycero-phosphoethanolamine (synthetic, purity $>99 \%$ ), LPE (P); 1-palmitoyl-2-hydroxy-sn-glycero-3-[phospho-rac(1-glycerol)] monosodium salt (synthetic, purity $>99 \%$ ), LPG (P); 1-stearoyl-2-hydroxy-snglycero-3-phosphoinositol (liver, purity $>99 \%$ ), LPI (S); and 1-oleoyl-2-hydroxy-sn-glycero-3-[phosphoL-serine] monosodium salt (synthetic, purity $>99 \%$ ), LPS (O) were purchased from Avanti Polar Lipids, Inc. (Alabaster, AL, USA). (-)-Adenosine 5'-monophosphate monohydrate (99\%), AMP, and sodium hydroxide $(99.99 \%)$ were from Aldrich (Milwaukee, WI, USA). Human serum, HPLC grade methanol $(>99.9 \%)$, acetonitrile $(>99.9 \%)$ and 8-anilino-1naphthalenesulfonic acid were obtained from Sigma (St. Louis, MO, USA). Boric acid (electrophoresis purity reagent) was from Bio-Rad Laboratories (Richmond, CA, USA). Chloroform, ammonium hydroxide, hydrochloric acid, and Whatman flexiblebacked TLC plates $(60-\AA$ silica gel medium without fluorescent indicator, Whatman no. 4410221) were purchased from Fisher Scientific (Fair Lawn, NJ, USA).

Aqueous solutions were prepared with deionized water from Barnstead/Thermolyne NANOpure system (Dubuque, IA, USA). Stock buffer solutions of $50 \mathrm{~m} M$ AMP in various concentrations of boric acid were prepared by dissolving the appropriate amounts of AMP and boric acid in deionized water and adjusted to the desired $\mathrm{pH}$ values with $1 \mathrm{M} \mathrm{NaOH}$. The stock buffer solutions were filtered through a $0.45-\mu \mathrm{m}$ cellulose acetate membrane syringe filters (Alltech Associates, Inc., Deerfield, IL) before use. Separation buffer solutions of $5 \mathrm{~m} M$ AMP in various concentrations of boric acid were prepared by 10 fold dilution of the stock buffer solutions with methanol. The separation buffers $(100 \mathrm{ml}$ each) were degassed in an ultrasonic bath for $30 \mathrm{~min}$ before use. Stock standard solutions of $5 \mathrm{~m} M$ lysophospholipids were prepared in methanol-chloroform $(2: 1 \mathrm{v} / \mathrm{v})$. Prior to CE analysis, working standard solutions of lysophospholipids were freshly prepared by serial dilution of the stock standard solutions with the 
solvent of 5\% separation buffer in methanol-water $(9: 1 \mathrm{v} / \mathrm{v})$.

\section{Instrumentation}

Open tubular fused-silica capillary (75- $\mu \mathrm{m}$ I.D., 354- $\mu \mathrm{m}$ O.D.) was obtained from Polymicro Technologies (Phoenix, AZ). The uncoated capillary was $47 \mathrm{~cm}$ in length (40 $\mathrm{cm}$ to the detection window). This capillary was mounted in a P/ACE cartridge that was connected to a temperature control system. A new capillary was conditioned sequentially with $0.1 \mathrm{M} \mathrm{NaOH}$ for $1 \mathrm{~h}$, deionized water for $20 \mathrm{~min}$, methanol for $20 \mathrm{~min}$, and separation buffer for 30 min before use. As a daily routine procedure, the capillary was rinsed with $0.1 \mathrm{M} \mathrm{NaOH}$ for $5 \mathrm{~min}$, deionized water for $2 \mathrm{~min}$, and separation buffer for 15 min.

A Beckman (Fullerton, CA) P/ACE 2200 system and an IBM PC with System Gold software (Version 8.1) were used for CE separation. On-line indirect $\mathrm{UV}$ detection was performed at $254 \mathrm{~nm}$, and the separation temperature was maintained at $25^{\circ} \mathrm{C}$ unless otherwise specified. Samples were introduced into the capillary by pressure injection at $3.45 \mathrm{kPa}$ for $5 \mathrm{~s}$. Separations were carried out under applied potential of $25 \mathrm{kV}$ at the normal polarity (the cathode was placed at the outlet of the capillary) unless otherwise specified. Between runs, the capillary was rinsed with the separation buffer for $2 \mathrm{~min}$.

A Hewlett-Packard (Wilmington, DE) HP 8453 UV-Visible spectrophotometer and a HP PC with ChemStation software were used for taking the UV spectra of the background electrolyte and LPA.

\section{Serum samples preparation}

Extraction of serum lipids was performed at 0 $4^{\circ} \mathrm{C}$ to minimize damage to ester bonds. The procedure developed by Bligh and Dyer [12] was used with modifications: $1 \mathrm{ml}$ serum spiked with $100 \mu M$ LPA (S), LPA (O), LPA (P), LPA (M) and LPA (D) was acidified by $0.2 \mathrm{ml}$ of $12 \mathrm{M} \mathrm{HCl}$, and mixed with $4 \mathrm{ml}$ of methanol-chloroform $(2: 1 \mathrm{v} / \mathrm{v})$ for 10 min. After adding $1 \mathrm{ml}$ of chloroform and $1.25 \mathrm{ml}$ of water, the mixture was centrifuged at $1000 \mathrm{~g}$ for 10 min. The methanol-chloroform phase (lower phase) containing lipids was pipetted, evaporated under $\mathrm{N}_{2}$ until remaining about $50 \mu \mathrm{l}$, and loaded on a TLC plate. The spot containing LPAs was separated from other lipids by TLC using the solvent system of chloroform-methanol-ammonium hydroxide (65:35: $5.5 \mathrm{v} / \mathrm{v} / \mathrm{v}$ ) [3]. To conform the position of LPA spot on the TLC plate for the first time, $0.1 \%$ of 8 anilino-1-naphthalenesulfonic acid in water was used as spray on the standard LPA and the lipid extraction after TLC separation. The LPA spot was visualized in a dark room under UV light. For subsequent separations, LPA spot was detected by water spray to prevent the contamination, scraped and extracted [12] from plate. The extract was evaporated under $\mathrm{N}_{2}$ to dryness. The dry powder was reconstituted in $1 \mathrm{ml}$ of 5\% separation buffer in methanol-water (9:1 $\mathrm{v} / \mathrm{v})$, and the solution was subjected to $\mathrm{CE}$ analysis.

\section{Results and discussion}

\section{Indirect $U V$ detection and $U V$-absorbing background electrolyte}

Direct UV spectrophotometry has been used for detection of PLs at the absorptive range of 200 to $210 \mathrm{~nm}$ [6]. However, due to the low UV absorptivity of carbonyl group of Lyso-PLs, direct UV detection of Lyso-PLs is not more sensitive than indirect UV detection. Particularly, when methanol and chloroform were used as solvents in this study, which exhibit absorptivities at around $200 \mathrm{~nm}$. Hence, indirect UV detection was used for this study.

In indirect UV detection, a chromophore is necessarily included in background electrolyte (BGE) to generate high background absorption at the UV detector. The displacement of UV-absorbing additive by the non-absorbing analytes results in negative analytical peaks [13].

For this work, $5 \mathrm{~m} M$ AMP was chosen as the UV-absorbing additive for detection because of its high molar absorptivity, large ratio of background absorbance to background noise (dynamic reserve), and favorable transfer ratio (the ratio of the solute charge to the charge of the UV-absorbing additive) [14], as well as closely matched mobility with LysoPLs. As shown in Fig. 2, the BGE (a 250-fold dilution of separation buffer) gave two maximum absorption peaks at 206 and $259 \mathrm{~nm}$, and the 


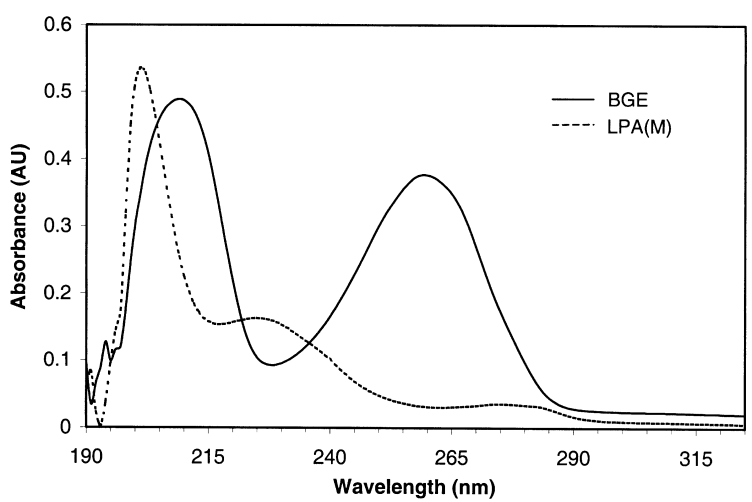

Fig. 2. The UV spectrum of BGE containing $20 \mu M$ AMP and 40 $\mu M \mathrm{H}_{3} \mathrm{BO}_{3}$ at $\mathrm{pH} 5.4$ in the solvent, methanol-water $(9: 1 \mathrm{v} / \mathrm{v})$, compared with the spectrum of $20 \mu M$ LPA (M) in the solvent. In these spectra, the solvent was used as the blank.

maximum difference of absorption between the LPA and BGE was at $259 \mathrm{~nm}$. The wavelength of $254 \mathrm{~nm}$ was used for the detection in the subsequent experiments because the 259-nm filter was not available.

\section{Organic solvent}

It is worth noticing that the use of $90 \%$ organic solvent in separation buffer is essential for the solubility and selectivity of PLs [11]. Methanol was used as the organic solvent in our experiments, because its solvation properties can reduce the hydrophobic interaction among the Lyso-PLs and its dielectric constant and viscosity can help to achieve desirable resolution [15]. The use of $10 \%$ acetonitrile and $80 \%$ methanol in the separation buffer was also tested for the separation of LPAs and the results were compared with those obtained from the buffer containing 90\% methanol alone. Although the migration times for all LPAs were shorter (within $9 \mathrm{~min}$ ) and the peaks were sharper than the separation performed in the buffer containing $90 \%$ methanol due to the lower viscosity of acetonitrile, the use of acetonitrile in the separation buffer resulted in poor resolutions (data not shown). Therefore, methanol-water (9:1 $\mathrm{v} / \mathrm{v})$ was used as the solvent for all subsequent separations.

\section{Separation of lysophosphatidic acids}

\section{Effect of boric acid}

Boric acid was used as the BGE in this work, which affects migration and detection of the LPAs. The effects of boric acid concentration on migration, resolution, and indirect signal response were shown in Fig. 3. Theoretically, an increase in BGE concentration lowers the $\zeta$ potential on fused-silica capillary wall. Therefore, it decreases the electroosmotic flow (EOF) and lengthens the migration time of analytes, which may improve or worsen the separation resolution. In addition, the signal response in indirect detection is directly related to the concentration ratio of $\mathrm{UV}$ additive and BGE. In this study, at the fixed concentration of UV additive (5 $\mathrm{m} M$ AMP), as the concentration of boric acid increased from 10 to $50 \mathrm{~m} M$, the migration time of LPA (M) increased ca. $1.3 \mathrm{~min}$, and the resolution of LPAs worsened due to the Joule heating at higher currents. Further, the indirect signal responses for LPAs were slightly lower in 50 than in $10 \mathrm{~m} M$ boric

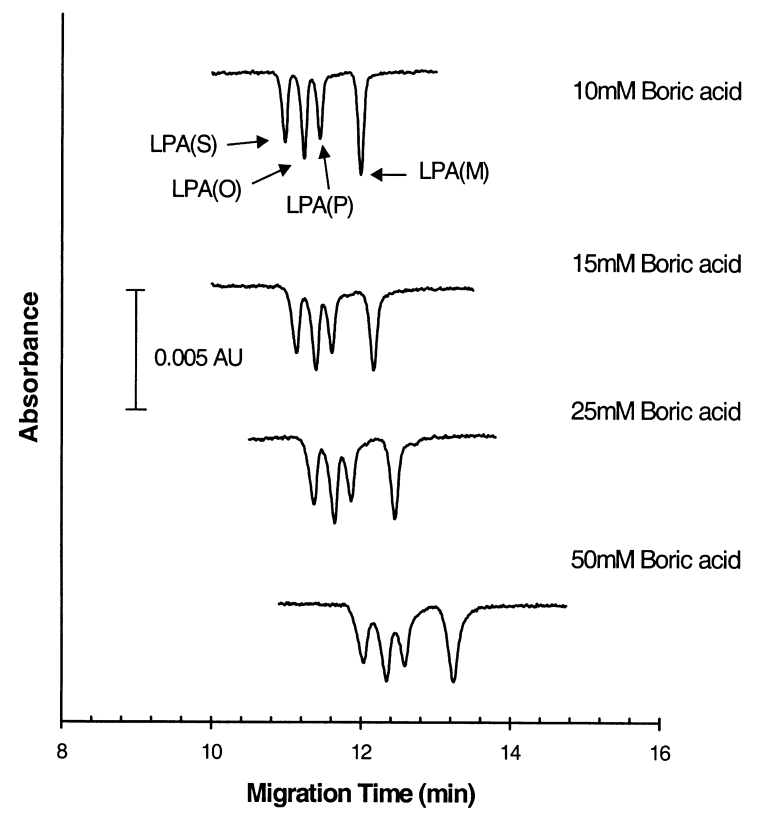

Fig. 3. The effect of boric acid on the separation of LPAs. The separation buffer was $5 \mathrm{mM}$ AMP and 10-50 $\mathrm{m} M$ boric acid at $\mathrm{pH} 5.4$ in methanol-water $(9: 1 \mathrm{v} / \mathrm{v})$. 


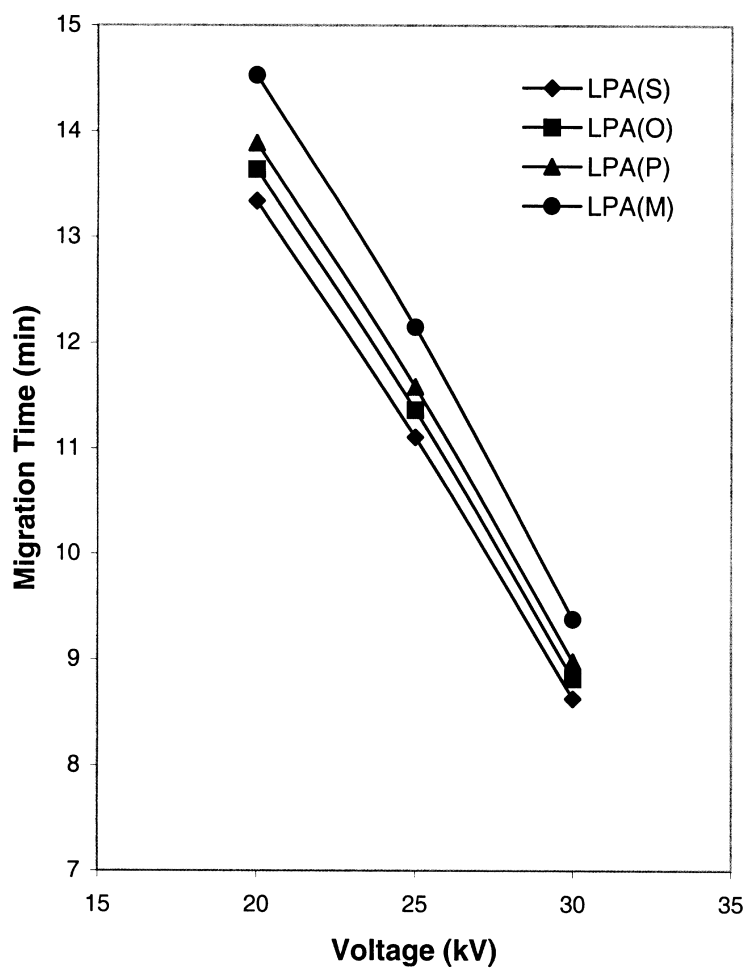

Fig. 4. The effect of applied voltage on the separation of LPAs. The separation buffer was $5 \mathrm{~m} M$ AMP and $10 \mathrm{~m} M$ boric acid at pH 5.4 in methanol-water $(9: 1 \mathrm{v} / \mathrm{v})$.

acid due to the lower displacement of AMP at higher concentration of boric acid. For all subsequent separations, $10 \mathrm{~m} M$ boric acid was used as BGE.

\section{Effect of applied voltage}

Applied voltage affects EOF, current and resolution. As shown in Fig. 4, the migration time of
LPAs decreased as applied voltage increased. The last LPA in the migration sequence was LPA (M). Its migration time decreased from 14.5 to $9.4 \mathrm{~min}$ as the applied voltage increased from 20 to $30 \mathrm{kV}$. However, the resolution of LPAs varied according to the applied voltage. The effect of applied voltage on the resolution of the two closely related LPA peaks, LPA (O) and LPA (P), was summarised in Table 1. The optimum resolution was obtained at $25 \mathrm{kV}$. Therefore, an applied voltage of $25 \mathrm{kV}$ was used for all subsequent separations.

\section{Effect of temperature}

Temperature affects many variables including $\mathrm{pH}$, injection volume, viscosity, EOF, sensitivity and resolution, current, ionic strength, and electrophoretic mobility. The effect of temperature on the separation of LPAs was shown in Fig. 5. The influence of temperature on resolution and migration time was summarized in Table 1 . The resolution of the LPAs decreased as temperature increased, which is probably attributed to the higher diffusion rates at higher temperatures. The migration time of the LPAs also decreased as temperature increased, which might be caused by the higher EOF at higher temperatures. A temperature of $25^{\circ} \mathrm{C}$ was chosen as for all subsequent studies.

\section{Effect of buffer $p H$}

Buffer $\mathrm{pH}$ is one of the most important parameters for the separation of ionic species. In this work, the $\mathrm{pH}$ influences not only the degrees of dissociation of boric acid, AMP and LPAs, but also the EOF of the capillary. Hence, it affects the apparent mobilities of LPAs, as well as the indirect signal response.

The effect of buffer $\mathrm{pH}$ on the separation of LPAs

Table 1

The effects of applied voltage, temperature and buffer $\mathrm{pH}$ on the separation of LPAs

\begin{tabular}{|c|c|c|c|c|c|c|c|c|c|c|}
\hline \multirow[t]{2}{*}{ Effect } & \multicolumn{3}{|c|}{ Applied Voltage $(\mathrm{kV})$} & \multicolumn{4}{|c|}{ Temperature $\left({ }^{\circ} \mathrm{C}\right)$} & \multicolumn{3}{|c|}{ Buffer $\mathrm{pH}$} \\
\hline & 20 & 25 & 30 & 20 & 22 & 25 & 30 & 5.4 & 6 & 7 \\
\hline $\begin{array}{l}\text { Resolution of } \\
\text { LPA }(\mathrm{O}) \text { and LPA (P) }\end{array}$ & 1.18 & 1.31 & 1.24 & 1.32 & 1.31 & 1.31 & 1.27 & 1.31 & 1.52 & 2.08 \\
\hline $\begin{array}{l}\text { Migration time of } \\
\text { LPA (M) (min) }\end{array}$ & 14.5 & 12.2 & 9.4 & 13.5 & 12.9 & 12.2 & 11.0 & 12.2 & 13.8 & 19.2 \\
\hline
\end{tabular}




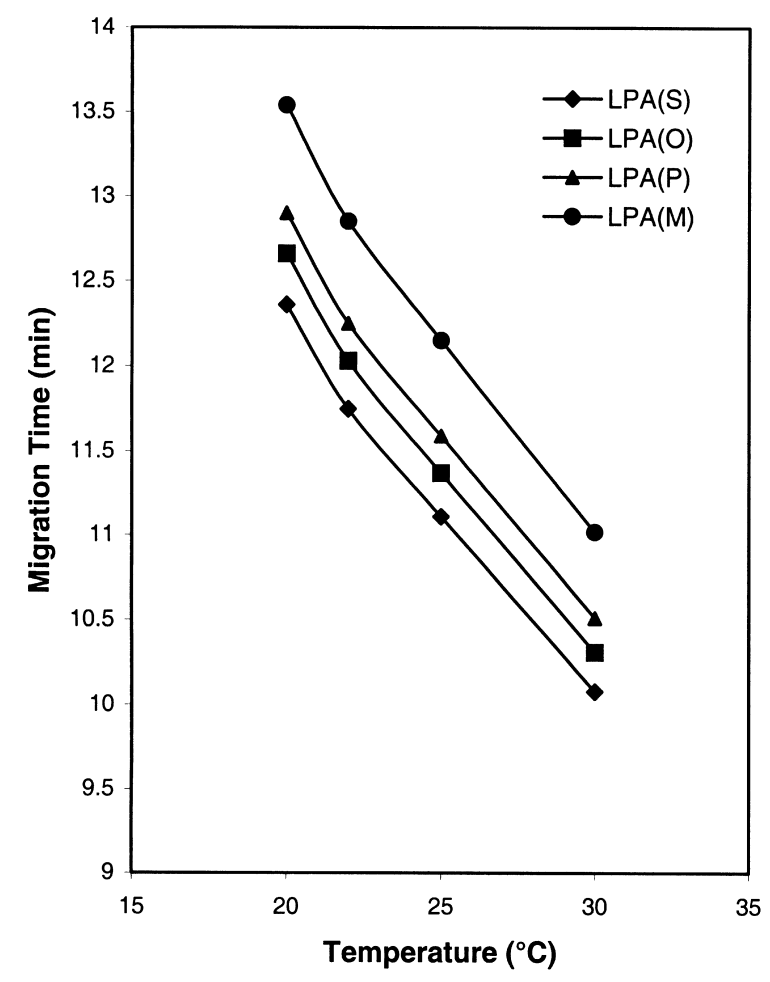

Fig. 5. The effect of temperature on the separation of LPAs. The separation buffer was $5 \mathrm{~m} M$ AMP and $10 \mathrm{~m} M$ boric acid at pH 5.4 in methanol-water $(9: 1 \mathrm{v} / \mathrm{v})$.

was shown in Fig. 6. It is remarkable that the higher the $\mathrm{pH}$, the slower were the migrations of LPAs. According to the manufacturer, the values of $\mathrm{p} K_{\mathrm{a}, 1}$ and $\mathrm{p} K_{\mathrm{a}, 2}$ for LPAs are 3-4 and 8-9, respectively. As the $\mathrm{pH}$ value increased from 5.4 to 7.0 , the molecular charges of LPAs increased from 1 negative to partial 2 negative. Moreover, the EOF also increased with increasing $\mathrm{pH}$, which was in the opposite direction of the electrophoretic forces of LPAs. Compared to the increased electrophoretic forces, the increased EOF was smaller in magnitude. Therefore, the apparent mobilities of LPAs were actually decreased under the higher $\mathrm{pH}$ values. The lower $\mathrm{pH}$ resulted in shorter migration time for the LPAs. However, if $\mathrm{pH}$ is below 5.4, it could cause problems such as current error and reduced solubility of AMP.

Although at higher $\mathrm{pH}$ values the signal responses became broader and shorter due to the longer diffusion at slower migration and the charge dis-

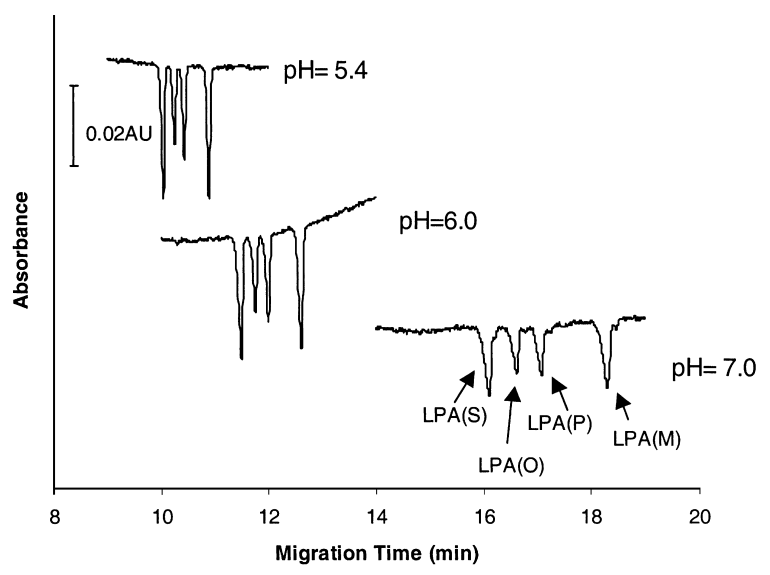

Fig. 6. The effect of buffer $\mathrm{pH}$ on the separation of LPAs. The separation buffer was $5 \mathrm{mM}$ AMP and $10 \mathrm{~m} M$ boric acid at $\mathrm{pH}$ $5.4-7.0$ in methanol-water $(9: 1 \mathrm{v} / \mathrm{v})$.

placement of UV-absorbing additive and BGE by analytes [13], the resolution of LPAs increased with increasing $\mathrm{pH}$ and migration time. As shown in Table 1, the resolution of LPA (O) and LPA (P) increased from 1.31 to 2.08 with increasing $\mathrm{pH}$ from 5.4 to 7.0 and migration time from 12.2 to $19.2 \mathrm{~min}$. A $\mathrm{pH}$ of 5.4 was used for all subsequent studies.

Separation of lysophosphatidic acids in presence of other lysophospholipids

The optimum conditions were applied to the separation of LPAs in the presence of other anionic Lyso-PLs (i.e., LPI, LPS, LPG). As shown in Fig. $7 \mathrm{a}$, the migration order was LPI $>$ LPS $>$ LPG $>$ LPA. The species with the least negative charge-to-mass ratio eluted first and the species with the most negative charge-to-mass ratio eluted last at the outlet of the capillary where the cathode was placed. It is worth noted that there were considerable capacities among the LPI, LPS, LPG peaks for the further separation of these Lyso-PLs with various length of fatty acyl groups. Separation of neutral Lyso-PLs, LPC and LPE, were attempted under the same conditions, but there were no separation. These neutral Lyso-PLs eluted together with the system peak (ca. $5 \mathrm{~min}$ ) which had the same mobility as the EOF. 


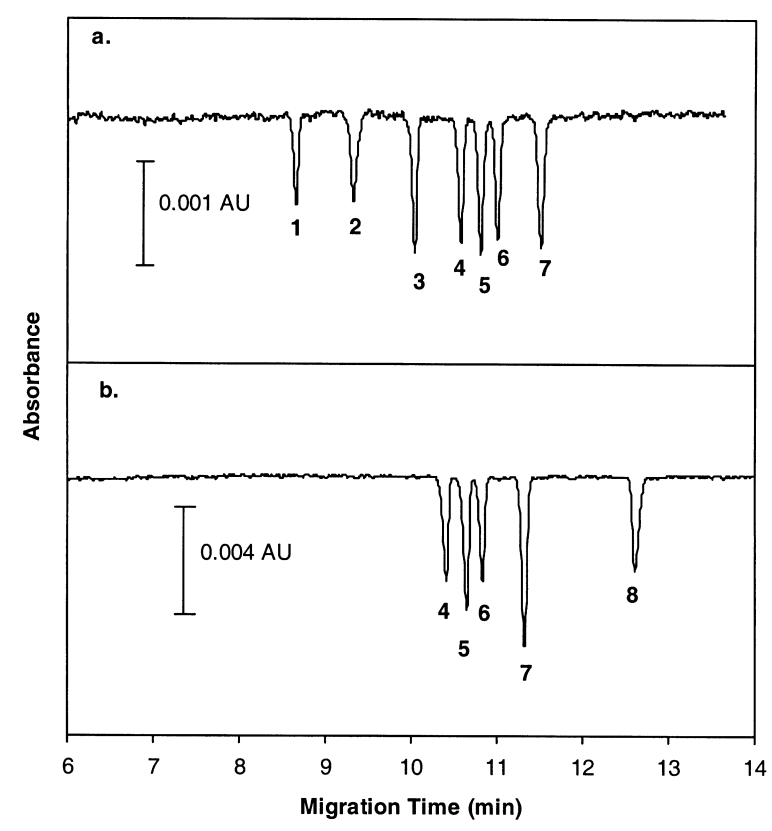

Fig. 7. (a) The electropherogram for the separation of lysophospholipids; and (b) the electropherogram for the separation of lysophosphatidic acids. Peak identities: 1, LPI(S); 2, LPS(O); 3, LPG(P); 4, LPA (S); 5, LPA (O); 6, LPA (P); 7, LPA (M); 8, LPA (D), internal standard. The separation buffer was $5 \mathrm{mM}$ AMP and $10 \mathrm{~m} M$ boric acid at pH 5.4 in methanol-water $(9: 1 \mathrm{v} / \mathrm{v})$.

\section{Quantitative analysis of lysophosphatidic acids}

Quantitative analysis of LPAs was carried out with the method of internal calibration. Internal calibration usually results in better precision compared to direct calibration because neither the injection quantities nor the detector response is required to remain constant. Therefore, it can eliminate the errors caused by the variation of sample injection and UV
Table 3

The performance of capillary column

\begin{tabular}{|c|c|c|c|}
\hline \multirow[t]{2}{*}{ Compound } & \multicolumn{2}{|c|}{ Relative migration time ${ }^{a}$} & \multirow[t]{2}{*}{$N^{\mathrm{b}}$} \\
\hline & Mean & \%C.V. & \\
\hline LPA (M) & $0.892 \pm 0.0049$ & 0.55 & 115000 \\
\hline LPA (P) & $0.852 \pm 0.0061$ & 0.72 & 117000 \\
\hline LPA $(\mathrm{O})$ & $0.837 \pm 0.0065$ & 0.78 & 116000 \\
\hline LPA (S) & $0.818 \pm 0.0070$ & 0.86 & 120000 \\
\hline
\end{tabular}

lamp intensity, as well as high volatility of solvent (e.g., methanol and chloroform). In this work, LPA (D) was chosen as the internal standard (I.S.) because it is not an endogenous compound. Fig. 7b showed the separation of standard LPAs from I.S. The complete separation of LPA (S), LPA (O), LPA (P), LPA (M), and LPA (D) was accomplished in less than 14 min.

The merits of analytical performance of the method were summarized in Table 2. The calibration plot for each molecular species of LPA was linear from 2.8 to $75 \mu M$ determined by the mean of three measurements at each of the six concentrations $(2.8$, $4.5,11,29,47$ and $75 \mu M)$. The linear correlation coefficients were greater than 0.999 . The detection limits of LPAs were ranged from 1.2 to $2.3 \mu M$. The repeatabilities of the area ratio (the peak area of LPA vs. the peak area of I.S.) calculated as \%C.V. were less than $10 \%$.

The performance of capillary column was given in Table 3. The relative migration time is defined as the migration time of a LPA peak divided by the migration time of a reference peak. Using the I.S.

Table 2

Analytical performance of the method

\begin{tabular}{|c|c|c|c|c|}
\hline \multirow[t]{2}{*}{ Compound } & \multicolumn{2}{|l|}{ Calibration plot } & \multirow{2}{*}{$\begin{array}{l}\text { Repeatability of } \\
\text { area ratio }(\% \text { C.V. })^{\mathrm{a}}\end{array}$} & \multirow[t]{2}{*}{$\mathrm{DL}(\mu M)^{\mathrm{b}}$} \\
\hline & Least square equation & $R^{2}$ & & \\
\hline LPA (M) & $y=0.0523 x+0.0457$ & 0.9996 & $2.2-5.4$ & 2.0 \\
\hline LPA $(\mathrm{P})$ & $y=0.0503 x+0.0255$ & 0.9996 & $1.7-9.2$ & 2.3 \\
\hline LPA (O) & $y=0.0561 x+0.0007$ & 1.0000 & $0.9-9.9$ & 1.8 \\
\hline LPA (S) & $y=0.0521 x+0.0345$ & 0.9999 & $1.4-9.7$ & 1.2 \\
\hline
\end{tabular}

${ }^{\mathrm{a}} n=3$, the LPAs were at $2.8,4.5,11,29,47$ and $75 \mu M$, and the internal standard was at $20 \mu M$.

${ }^{\mathrm{b}} \mathrm{DL}$, detection limit, was calculated by the least square equation at $S / N=3$. 
peak as a reference, the reproducibility of relative migration time for each LPA peak was very good $(\%$ C.V. $\leq 0.86)$. The separation efficiency calculated based on the equation, $N=5.54\left(L_{d} / W_{1 / 2}\right)^{2}$ (where $L_{d}=40 \mathrm{~cm}$, the length of the capillary from inlet to the detector, and $W_{1 / 2}=$ the peak width at halfheight) was 115000-120000 at each LPA concentration of $11 \mu M$.

\section{Serum sample analysis}

Human serum fortified with LPA (S), LPA (O), LPA (P), LPA (M) and internal standard LPA (D) was prepared by liquid-liquid extraction and TLC according to the procedure described in the Section 2.3. The sample was then analyzed by the $\mathrm{CE}$ method. As shown in Fig. 8b, the separation of LPAs in serum was successfully achieved. Although the migration times of LPAs had shifted for ca. $1 \mathrm{~min}$ (due to the matrix effect) compared to those in Fig. $7 \mathrm{~b}$, the relative migration times remained the same. The relative recoveries [defined as the area ratio of the serum sample (the peak area of LPA vs. the peak

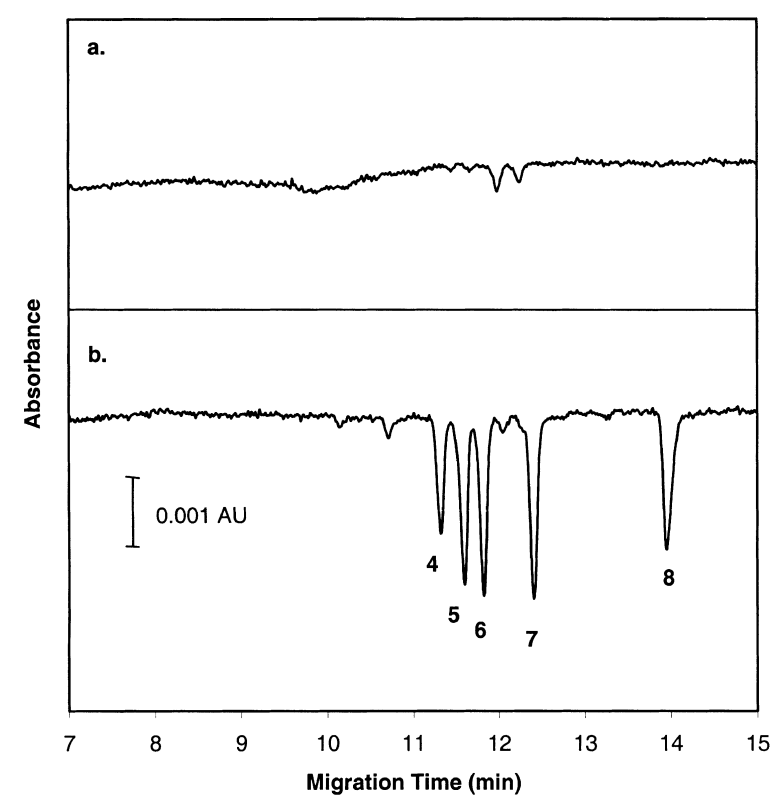

Fig. 8. The electropherograms for the separation of (a) the blank serum, and (b) LPAs in serum sample. Sample preparation procedure was given in the Section 2.3, and the separation conditions and peak numbers were the same as those in Fig. 7. area of I.S.) divided by that of the standard solution] for LPA (S), LPA (O), LPA (P), and LPA (M) were $83,110,112$, and $111 \%$ respectively. As seen in Fig. $8 \mathrm{~b}$, there were trace amounts of other anionic LysoPLs present in the electropherogram because the TLC separation was not complete, and these anionic Lyso-PLs did not interfere with the LPA detection by the CE method. This method shows great potential for clinical application. The authors also believe that the procedure used for serum pretreatment was laborious and time-consuming. Therefore, effort is being taken for developing one-step solid-phase extraction procedure for blood samples.

\section{Conclusions}

This paper has reported a simple CE method for the quantitative analysis of molecular species of LPA. The separation of LPAs was achieved within 14 $\min$ in an adenosine monophosphate-borate-methanol-water solution, and the measurement was accomplished by indirect UV detection. The method was optimized in terms of UV-absorbing additive, organic modifier, background electrolyte, applied potential, temperature, and $\mathrm{pH}$. With internal calibration, the method has linear calibration ranges for LPAs from 2.8 to $75 \mu M$ with correlation coefficients greater than 0.999 . The detection limits for various molecular species of LPA were from 1.2 to $2.3 \mu M$ by the pressure injection at $3.45 \mathrm{kPa}$ for $5 \mathrm{~s}$. The method may be used in clinical diagnosis of ovarian cancer.

\section{Acknowledgements}

This project was supported by the University Graduate Council of the Cleveland State University.

\section{References}

[1] M.E. Durieux, K.R. Lynch, Trends Pharmacol. Sci. 14 (1993) 249.

[2] Y. Xu, D.C. Gaudette, J.D. Boynton, A. Frankel, X.-J. Fang, A. Sharma, J. Hurteau, G. Casey, A. Goodbody, A. Mellors, B.J. Holub, G.B. Mills, Clin. Cancer Res. 1 (1995) 1223. 
[3] Y. Xu, Z. Shen, D.W. Wiper, M. Wu, R.E. Morton, P. Elson, A.W. Kennedy, J. Belinson, M. Markman, G. Casey, J. Am. Med. Assoc. 280 (1998) 719.

[4] Z. Shen, Ph.D. Dissertation, Cleveland State University, Cleveland, OH, 1998.

[5] K. Satouchi, T. Mizuno, Y. Samejima, K. Saito, Cancer Res. 44 (1984) 1460.

[6] G.M. Patton, J.M. Fasulo, S.J. Robins, J. Lipid Res. 23 (1982) 190.

[7] Y. Xu, Anal. Chem. 67 (1995) 463R.

[8] L. Ingvardsen, S. Michaelsen, H. Sorensen, J. Am. Oil Chem. Soc. 71 (1994) 183.

[9] R. Szucs, K. Verleysen, G.S.M.J.E. Duchateau, P. Sandra, B.G.M. Vandeginste, J. Chromatogr. A 738 (1996) 25.
[10] K. Raith, R. Wolf, J. Wagner, R.H.H. Neubert, J. Chromatogr. A 802 (1998) 185.

[11] F. Haddadian, S.A. Shamsi, J.P. Schaeper, N.D. Danielson, J. Chromatogr. Sci. 36 (1998) 395.

[12] E.G. Bligh, W.J. Dyer, Can. J. Biochem. Physiol. 37 (1959) 911.

[13] H. Chen, Y. Xu, F. Van Lente, M.P.C. Ip, J. Chromatogr. B 679 (1996) 49.

[14] S.A. Shamsi, N.D. Danielson, Anal. Chem. 67 (1995) 1845.

[15] H. Salimi-Moosavi, R.M. Cassidy, Anal. Chem. 68 (1996) 293.

Post-print standardized by MSL Academic Endeavors, the imprint of the Michael Schwartz Library at Cleveland State University, 2017. 